\title{
The experience of patient suicide among trainees in psychiatry ${ }^{\dagger}$
}

\author{
AIMS AND METHOD \\ We set out to ascertain how \\ common this is for psychiatric \\ trainees in South Thames and the \\ effects it has, if any. An anonymous \\ postal questionnaire was circulated \\ to 400 trainees.
}

\author{
RESULTS \\ Of the 400 trainees, 203 (51\%) \\ responded and $109(54 \%)$ of the \\ respondents had had one or more \\ patient suicide and 168 suicides were \\ reported. We judged the effect of the \\ suicide on the doctor to be moderate
}

\author{
or severe in $126(75 \%)$ of the 168 \\ suicide events. \\ CLINICAL IMPLICATIONS \\ Patient suicide must have a higher \\ profile in training. Formal systems \\ need to be created to provide \\ support and education in this area.
}

A study in Australia identified suicide of a patient as one of the principal adversities of training in psychiatry (Kozlowska et al, 1997). Having had personal experience of patient suicide we were interested to learn about the experience of other trainees in our region. How common is it? What is the personal impact of the death? What support is available to the doctor?

\section{The study}

A review of literature was carried out using MEDLINE. A questionnaire was designed to gather information from trainees in the South Thames region of the UK. The questionnaire requested details of the trainee, any suicides experienced, the personal effect of the event and any specific support given to the trainee. We were interested to learn of any impact of the suicide on clinical practice or choice of career. The questionnaire was circulated to 400 trainees in the region, covering three London teaching hospitals rotations. The questionnaire was anonymous. From the respondents reporting the experience, we analysed the description of the personal effects and graded these as minimal, moderate or severe emotional impact. Each of us rated these independently for every suicide event. The ratings were compared. Where a discrepancy occurred between ratings we opted for the category of lesser emotional impact.

\section{Findings}

Of the 400 questionnaires distributed, we received 203 responses, a response rate of $51 \%$. Among the respondents, 109 (54\%) had had a patient under their care who had committed suicide. Of the total sample, 105 (51\%) were male and $98(49 \%)$ were female. The mean age was 32 years (range $24-47$ years). There were 130 (64\%) senior house officers and 73 (36\%) senior registrars/ specialist registrars, with a mean of 3.5 years in training (range 1-11 years).

A total of 168 patient suicides were reported by the 109 positive respondents. Sixty-seven (61\%) had experienced a single suicide and 42 (39\%) more than one (1-7). Trainees experienced 168 patient suicides in a total of 735.5 training years, giving a rate of 0.23 suicides per training year, that is, approximately one suicide in every 4 years of training.

We graded the narrative responses for each of the 168 patient suicide events. Expressions of extreme guilt or anger, especially of prolonged duration, were assessed as indicating a severe emotional reaction. Similarly, words such as devastated, disturbing and paranoid fell into the same category, as did trainees who required time off work or suggested they had lost confidence in their clinical judgement. The moderate category described lesser degrees of emotional impact, for example, shock, guilt or self-blame of shorter duration. Emotional impact was considered to be absent or minimal in $23(14 \%)$, moderate in $86(51 \%)$ and severe in $40(24 \%)$ suicide events. This information was not provided in $19(11 \%)$ cases (Table 1$)$.

In the aftermath of 77 (46\%) of the 168 suicide events trainees expressed the need for help in coping with the emotional upset. Of the 77 , help was offered in $46(60 \%)$ cases, although the need was ignored in 31 (40\%). The form of help offered varied, but was most commonly either support through individual consultant supervision or through the community mental health team. This support was appreciated. The only adverse comments related to cases where external counsellors provided 'debriefing'. Those who did not feel that they $\dagger$ See editorial, pp. 41-42 this issue and pp. 43-50 and pp. $53-55$ this issue 
Table 1. Emotional impact of patient suicide events

original

papers

\begin{tabular}{|lll} 
& \multicolumn{2}{l}{ Trainees $(n=203)$} \\
\cline { 2 - 3 } & $\begin{array}{l}\text { Patient suicide } \\
\text { (109: range 1-7) }\end{array}$ & $\begin{array}{l}\text { No patient suicide } \\
(94)\end{array}$ \\
\hline $\begin{array}{l}\text { Total suicide events } \\
\text { Emotional impact: }\end{array}$ & 168 & 0 \\
$\quad$ Minimal & $23(14 \%)$ & N/A \\
$\begin{array}{l}\text { Moderate } \\
\text { Severe }\end{array}$ & $86(51 \%)$ & N/A \\
No information & $40(24 \%)$ & N/A \\
\hline
\end{tabular}

needed help at the time cited friends and peers as having filled this role. It appeared for some that to admit to an emotional response would be unprofessional.

Of the 109 trainees who had experienced a patient suicide, 74 (68\%) believed that it had had an impact on their clinical practice. We adjudged that in 57 of these cases this impact could be described as beneficial and in 17 as adverse. Beneficial outcomes included individuals learning from the experience to develop more thorough and comprehensive risk assessment skills. In fact it was valued as a formative experience in training for some trainees. Negative outcomes included doctors who became afraid of clinical contact, felt isolated, disillusioned, vulnerable and lacking in confidence or became excessively preoccupied by medico-legal considerations. Surprisingly, virtually no respondents admitted that these suicides had influenced their career choice.

\section{Comments}

Our response rate of $51 \%$ to an anonymous postal survey compares favourably with similar studies by Chemtob et al (1988) and Kozlowska et al (1997). Nevertheless, a suspicion remains that the respondents may be biased in favour of those who have had an experience of patient suicide. We attempted to minimise the potential bias among respondents who had experienced patient suicide by asking a question about colleagues whose patients had committed suicide in order to encourage the return of questionnaires by those not directly affected.

Fifty-four per cent of our respondents had experienced patient suicide, a similar percentage to that of Chemtob et al (1988) in the USA, although fewer than the $68 \%$ were identified by Kozlowska et al (1997) in Australia. Their samples were both drawn from more experienced groups, our sample possibly resembling more closely that of Brown (1987), who found the experience in $37 \%$ of 'residents' in the USA

Our sample was not sufficiently experienced as to have developed the relative immunity to the event that others have described. Chemtob et al (1988) found a negative correlation between the impact of a patient suicide and both age and years in practice.

In planning this study we considered including an objectively validated rating scale to assess the impact of the event. However, weighing the need for a good response rate from a brief questionnaire against a predicted lower response rate from a more onerous document, we opted for the latter. Hence our divisions into minimal, moderate or severe emotional reactions are necessarily subjective. If anything, we tended to underrate the emotional impact of the suicide by choosing the lesser rating where our ratings were conflicting.

It was gratifying to note from responses that almost any form of support offered in the period after a suicide was appreciated. The only exception to this was in the very few cases where outside counsellors were drafted in to assist, which was considered unhelpful. The consensus from our survey points to a need for some form of support to provide for ventilation of feelings, normalisation of the events, dissipation of ideas of guilt or blame or feelings of isolation. Ideally this should encourage learning from the experience. Cotton et al (1983) has suggested support is best provided in a group setting where it can have an important role in cementing a team and preventing the genesis of maladaptive and immature coping strategies. This might be useful for trainees who, by the transient nature of their work attachments, may be regarded as uniquely vulnerable. However, those trainees who cited strong positive and supportive consultant supervision expressed this as the only requirement. We therefore shy away from making specific recommendations, preferring to regard patient suicide as an occupational hazard to be openly discussed, anticipated and prepared for.

At a time when retention within and recruitment to the profession are increasing problems, there is a need for attention to mechanisms whereby psychiatrists can develop and maintain strong professional styles of coping that recognise their inherent limitations. Given our approximation that on average a trainee will experience one suicide among their patients in every 4 years of training and that in the majority of cases the emotional impact will be significant, we think that patient suicide must be given a higher profile in training. We call on programme directors and the Royal College of Psychiatrists to recognise the impact of patient suicide on trainees and to take steps to facilitate the creation of formal systems for support and education.

\section{References}

BROWN, H. N. (1987) The impact of suicide on therapists in training. Comprehensive Psychiatry, 28, 111-112.

CHEMTOB, C. M., HAMADA, R. S., BAUER, G., et al (1988) Patients' suicides: frequency and impact on psychiatrists. American Journal of Psychiatry, 145, 224-227.

COTTON, P. G., DRAKE, R. E. WHITAKER, A., et al (1983) Dealing with

suicide on a psychiatric inpatient unit. Hospital and Community Psychiatry, 34, 55-59.

KOZLOWSKA, K., NUNN, K. \& COUSENS, P. (1997) Adverse

experiences in psychiatric training. Part 2. Australian and New Zealand Journal of Psychiatry, 31, 641-652.

*Kenneth P. Courtenay Specialist Registrar, John P. Stephens Senior Registrar, Department of Psychiatry, St George's Hospital Medical School, Jenner Wing, CranmerTerrace, London SW17 ORE, e-mail: kcourten@sghms.ac.uk 